\title{
How many can you catch? Factors influencing the occurrence of multi-prey loading in provisioning Greater Crested Terns
}

\author{
Davide Gaglio $^{1, *}$, Timothée R Cook ${ }^{1,2}$, Richard B Sherley ${ }^{1,3}$, Peter G Ryan ${ }^{1}$
}

${ }^{1}$ FitzPatrick Institute, DST-NRF Centre of Excellence, University of Cape Town, Rondebosch 7700,

\author{
South Africa \\ ${ }^{2}$ Institute of Ecology and Environmental Sciences, Department of Evolutionary Ecology, Evolutionary \\ Ecophysiology Team, University Pierre and Marie Curie, Paris, France \\ ${ }^{3}$ Environment and Sustainability Institute, University of Exeter, Penryn, Cornwall, United Kingdom \\ *Corresponding author, email: swift.terns@gmail.com
}

\begin{abstract}
Seabirds use several methods to transport food to their chicks; most species carry food in their stomachs or crops, but some terns and auks carry prey in their bills. Terns usually only carry one prey item at a time, limiting the rate at which they can provision their chicks, and restricting their effective foraging range. However, some terns do occasionally carry multiple prey, which should offer a selective advantage, but there are very few studies investigating the factors influencing the occurrence of multi-prey loading. We investigated the occurrence of multi-prey loads in provisioning Greater Crested Terns (Swift Tern) Thalasseus bergii bergii breeding on Robben Island, South Africa. Of 24,173 loads photographed, $1.3 \%$ comprised multiple prey items. Up to 11 fish were carried at once, but most multiprey loads contained two Anchovies Engraulis encrasicolus, the most common prey item for this population of terns. Mixed species prey were recorded for the first time in a tern. Multi-prey loads occurred more frequently during mid- and lateprovisioning, presumably because large chicks can cope with multiple prey, and have higher energetic requirements than small chicks. Mean standard length of Anchovies in multi-prey prey loads was less than Anchovies in single loads, possibly suggesting terns compensate for smaller prey sizes by bringing multiple prey back to their chick. The orientation of multiple Anchovies in a tern's bill tended to be the same, suggesting that they were captured from polarized fish schools. At least some multi-prey loads were caught in a single dive.
\end{abstract}

Keywords: Thalasseus bergii bergii, photo-sampling, foraging strategy, fish size, prey orientation

Central place foragers must capture sufficient prey to sustain their energetic needs and those of their offspring (Orians and Pearson 1979; Burke and Montevecchi 2009). Seabirds breed in an environment where prey resources are patchily distributed (Berg et al. 2010). Transporting food in the stomach or crop, and transferring it to a chick by regurgitation, 
allows adults to optimise the time spent at sea. However, there is a limit to how much a seabird can carry in this way, restricted by stomach/crop volume, and the costs of transport (flight in particular) increase with body mass (e.g. Mullers et al. 2009). Instead of swallowing their prey, some seabird species (e.g. most terns, Sterninae, and some auks, Alcidae) carry prey in their bill. So-called 'multi-prey bill-loaders' can transport several fish in their bill, potentially optimizing the energy returned from each trip. This may be particularly useful in long distance foragers (Ydenberg 1994; Davoren and Burger 1999). Atlantic Puffins Fratercula arctica, for example, travel up to $66 \mathrm{~km}$ during each provisioning trip (Harris et al. 2012) and can hold up to 80 fish at a time crosswise in their bill (Barrett 2002; Harris and Wanless 2011). By comparison, species that carry only one prey at a time (so-called 'singleprey bill-loaders', e.g. guillemots Uria spp. and most terns) return to the colony each time they catch a suitable prey item for their offspring (McLeay et al. 2009; Stienen et al. 2015). These differences in strategy are often considered to be linked to differences in foraging range, with inshore foragers typically carrying a single prey item (e.g. Sandwich Terns Thalasseus sandvicensis; Fijn et al. 2016) and long-distance foragers carrying multiple prey (e.g. Razorbill Alca torda; Benvenuti et al. 2001), because the costs of transport increase with foraging range. In addition, differences in strategy may also be linked to seabird morphology, as some species have a longer bill and wider gape, allowing for the loading of more prey.

Although a few species of terns are known to regurgitate food to their chicks (e.g. Onychoprion terns), most tern species (66\%) are considered to be habitual single-prey loaders; only one species, the White Tern Gygis alba, typically carries multiple prey (Hockey \& Wilson 2009). Multi-prey loads are observed occasionally in coastal species that typically carry only one prey item (percentage of all loads): Sandwich (2.2\%), Common Sterna hirundo (1.7\%), Arctic S. paradisaea (1.7\%), Roseate S. dougallii (1.5\%) and Greater Crested Thalasseus bergii $(0.6 \%)$ terns (Hays et al. 1973; Duffy 1987). This behaviour appears to be opportunistic; carrying more than one prey item has benefits in terms of delivering more prey per foraging trip, but it likely reduces aerial agility and bill-grasping 
ability (reducing the ability to catch successive prey items) and may increase the risk of kleptoparasitism (Hays et al. 1973; Hulsman 1976; Duffy 1987). It has been suggested that multi-prey loads mainly occur when food is abundant, which facilitates multiple loading, while outweighing the costs of piracy (Hockey \& Wilson 2009). However, few studies have assessed the occurrence of multi-prey loads in facultative multi-prey loading terns (Hays et al. 1973, Duffy 1987). Little, if anything, is known about how multi-prey loads are captured, or how their incidence varies in relation to chick stage.

We report the occurrence of multi-prey loads in provisioning Greater Crested (Swift) Terns breeding at Robben Island $\left(33^{\circ} 48^{\prime} S 18^{\circ} 22 ' E\right)$, South Africa, during three consecutive breeding seasons. The incidence of multiple loads were assessed using a photo-sampling method of adults returning to their colony carrying prey items (Gaglio et al. 2017). Images were analysed to assess species composition and prey standard length of both single and multi-prey loads. For each load, the direction the fish were facing (orientation; left or right) was recorded in order to investigate whether or not the load followed a regular arrangement (Figure 1).

Of the 24,607 prey items identified, $739(3 \%)$ occurred in multi-prey loads ( $n=305)$, representing $1.3 \%$ of all loads $(n=24,173)$. Most multi-prey loads consisted of two fish $(n=$ 220 double loads; $72 \%$ of all multi-prey loads), with a maximum record of 11 fish carried in one trip (Figure 1b, Figure 2). The proportion of multi-prey loads photographed was more than double that observed by Duffy (1987) in the same species ( $0.6 \%$ of 2,639 loads). Most multi-prey loads comprised the same species, with Anchovy Engraulis encrasicolus (the most common prey item) being the sole species in $95 \%$ of all multi-prey loads. However, unlike Duffy (1987), we did record at least six multi-prey loads comprising more than one species. In all cases, they contained Anchovies and one individual of the following species: Sardine Sardinops sagax (Figure 1c), Redeye Round-herring Etrumeus whiteheadi, Atlantic Saury Scomberesox saurus and Horse Mackerel Trachurus capensis. To our knowledge, this is the first record of mixed species loads in a seabird species that typically only carries single prey items (Hays et al. 1973). Monospecific multi-prey loads other than Anchovies 
also were recorded, including loads with up to five Cape Silversides Atherina breviceps, and double loads of Sardines, Mullets (Liza sp.), Redeye Round-herrings, and Two-Spotted Crickets Gryllus bimaculatus. The crickets presumably were collected on land close to the breeding colony (Gaglio et al. 2015).

Most multi-prey loads occurred during mid- and late-chick provisioning; this was particularly evident during the second week of late provisioning in 2013 (Figure 3). The increase in multi-prey loads at the later stage of the season may indicate a behavioural adjustment to address the higher energy needs of large, mobile chicks, which (unlike small chicks) are able to cope with multiple prey (Klaassen et al. 1989). In parallel, this could also correspond to an increased availability in prey, as the timing corresponds to the seasonal peak in Anchovy recruits in the system (Hutchings et al. 2002). Adults provisioning hatchlings are constrained by the gut capacity of these chicks and high frequencies of kleptoparasitic attacks (Gaglio 2017). Thereafter, while provisioning mobile chicks, terns use several methods to reduce kleptoparasitism, such as attracting chicks away from parasitic individuals (Stienen and Brenninkmeijer 1999). Thus, the higher rates of multi-prey loads during later chick rearing may occur because behavioural strategies allow prey theft to be reduced efficiently at this stage.

Fish were oriented the same way in the adults' bills much more often than expected by chance $\left(\chi^{2}\right.$ tests; all $p$ values $<0.001$; Figure 4$)$. This regular arrangement of prey may derive from a single dive, where the bird seizes as many fish as possible from a polarised school, i.e. where fish are all swimming in the same direction (Wilson et al. 1987, Thiebault et al. 2016). That Great Crested Terns can catch multiple prey in a single plunge dive was confirmed when Barrie Rose photographed a dive sequence where a tern diving with an empty bill emerged at the sea-surface with a five Anchovy (Figure 1d). Greater Crested Terns may also be able to capture new prey while already holding one of more fish in their bill, an ability presumed to be important for habitual multi-prey loaders like White Terns, but there is no direct evidence of this. The occurrence of multi-species loads could be interpreted as evidence for capturing prey in multiple dives, but mixed-species loads may 
result from single dives into schools containing several species of juvenile clupeiformes, which are known to occur in the Benguela system (Fréon \& Dagorn 2000). Overall, taking into account the variety of feeding methods known for this species (plunge diving, surface seizing, aerial feeding, ground foraging, scavenging from seal catches, kleptoparasitism and perch hunting; Crawford et al. 2005, Ryan 2017), it is plausible to assume that Greater Crested Terns use several methods to capture these multi-prey loads.

The mean standard length $( \pm S D)$ of Anchovies in multi-prey loads $(70.0 \pm 13.9 \mathrm{~mm} ; n=$ 55) was less than the length of Anchovies occurring in single-prey loads caught at the same time as the multi-prey events $(82.1 \pm 16.5 \mathrm{~mm} ; \mathrm{n}=691$; permutation test: $p<0.001)$. These differences suggest some constraints due to prey size in habitual single prey loaders. The absolute mean $( \pm S D)$ difference between individual fish was $9.1( \pm 8.1) \mathrm{mm}$ in the $(n=18)$ double-prey loads and $15.1( \pm 14.1) \mathrm{mm}$ between the next two single prey loads brought to the colony (by different individuals) immediately afterwards. This difference was marginally not significant (Exact Permutation Test Estimated by Monte Carlo Simulations: $p=0.07 ; 99$ percent $\mathrm{Cl}$ on $\mathrm{p}$-value $0.061-0.072$ ) suggesting that, in this species, multi-prey loads can be caught from multiple dives.

This alternative multi-prey loading strategy, although occasional and opportunistic, may allow adults to provide food for their offspring more efficiently and is further evidence of the foraging plasticity observed in Greater Crested Terns (Gaglio et al. 2017). The photosampling technique applied here allowed us to investigate multi-prey loading in great detail, providing more insight into the biology of this coastal tern and offering a new understanding of this poorly studied foraging strategy. In light of the rapid miniaturisation of bio-logging devices, the future implementation of animal-borne video recorders (McGowan et al. 2016) may reveal further evidence of this infrequent, but presumably important behaviour.

Acknowledgments - Our research was supported by a Department of Science and TechnologyNational Research Foundation grant to the FitzPatrick Institute of African Ornithology Centre of Excellence, the Leiden Conservation Foundation (RBS) and our institutes. SANParks and Robben 
Island Museum provided logistical support and access to the tern colonies. This research was approved by SANParks (CONM1182), the Department of Environmental Affairs (RES2013/24, RES2014/83, RES2015/65) and the animal ethics committee of the University of Cape Town (2013/V3/TC). We thank Barrie Rose (deceased) for supplying Figure 1d.

\section{References}

Barrett RT. 2002. Atlantic puffin Fratercula arctica and common guillemot Uria aalge chick diet and growth as indicators of fish stocks in the Barents Sea. Marine Ecology Progress Series 230: 275-287.

Benvenuti S, Dall'Antonia LU, Lyngs P. 2001. Foraging behaviour and time allocation of chick-rearing Razorbills Alca torda at Græsholmen, central Baltic Sea. Ibis 143: 402-412.

Berg, MP, Kiers, ET, Driessen, G, Van Der Heijden, M, Kooi, BW, Kuenen, F, Liefting, M, Verhoef, HA, Ellers, J. 2010. Adapt or disperse: understanding species persistence in a changing world. Global Change Biology, 16: 587-598.

Burke CM, Montevecchi WA. 2009. The foraging decisions of a central place foraging seabird in response to fluctuations in local prey conditions. Journal of Zoology, London 278: 354-361.

Crawford RJM, Hockey PAR, Tree AJ. 2005. Swift Tern Sterna bergii. In: Hockey PAR, Dean WRJ, Ryan PG (eds), Roberts Birds of Southern Africa (7th edn). Cape Town: Trustees of the John Voelcker Bird Book Fund. pp 453-455.

Davoren GK, Burger AE. 1999. Differences in prey selection and behaviour during selffeeding and chick provisioning in rhinoceros auklets. Animal Behaviour 58: 853-863.

Duffy DC. 1987. Multiple fish-carrying in Swift Terns Sterna bergii. Cormorant 14: 46-49.

Fijn RC, de Jong J, Courtens W, Verstraete H, Stienen EWM, Poot MJM. 2016. GPStracking and colony observations reveal variation in offshore habitat use and foraging ecology of breeding Sandwich Terns. Journal of Sea Research 127: 203-2011. 
Fréon P, Dagorn L. 2000. Review of fish associative behaviour: Toward a generalisation of the meeting point hypothesis. Reviews in Fish Biology and Fisheries 10: 183-207.

Gaglio D, Sherley RB, Cook TR. 2015. Insects in the diet of the Greater Crested Tern Thalasseus bergii bergii in southern Africa. Marine Ornithology 43: 131-132.

Gaglio D, Cook TR, Connan M, Ryan PG, Sherley RB. 2017. Dietary studies in birds: testing a non-invasive method using digital photography in seabirds. Methods in Ecology and Evolution 8: 214-222.

Harris, MP, \& Wanless, S. 2011. The Puffin. London: Bloomsbury.

Harris, MP, Bogdanova MI, Daunt F, \& Wanless, S. 2012. Using GPS technology to assess feeding areas of Atlantic Puffins Fratercula arctica. Ringing \& Migration 27:43-49.

Hays H, Dunn E, Poole A. 1973. Common, Arctic, Roseate, and Sandwich Terns carrying multiple fish. Wilson Bulletin 85: 233-236.

Hockey PA, Wilson WA. 2009. Reproductive traits of marine terns (Sternidae): evidence for food limitation in the tropics? Ostrich 74: 110-116.

Hulsman K. 1976. The robbing behaviour of terns and gulls. Emu 76: 143-149.

Hutchings L, Beckley, LE, Griffiths, MH, Roberts, MJ, Sundby, S, van der Lingen, CD. 2002. Spawning on the edge: spawning grounds and nursery areas around the southern African coastline. Marine Freshwater Research 53: 307-318.

Kacelnik A. 1984. Central place foraging in starlings (Sturnus vulgaris). I. Patch residence time. Journal of Animal Ecology 53: 283-299.

Klaassen M, Bech C, Masman D, Slagsvold G. 1989. Growth and energetics of Arctic Tern chicks (Sterna paradisaea). Auk 106: 240-248.

Lee NM, Hockey PA. 2001. Biases in the field estimation of shorebird prey sizes. Journal of Field Ornithology 72: 49-61.

Orians GH, Pearson NE. 1979. On the theory of central place foraging. In: Horn, DJ, Mitchell, RD, Stairs, GR (eds), Analysis of ecological systems. Columbus: Ohio State University Press. pp154-177. 
McGowan J, Beger M, Lewison RL, Harcourt R, Campbell H, Priest M, Dwyer RG, Lin HY, Lentini P, Dudgeon C, McMahon C. 2017. Integrating research using animal-borne telemetry with the needs of conservation management. Journal of Applied Ecology 54: 423-429.

McLeay LJ, Page B, Goldsworthy SD, Ward TM, Paton DC. 2009. Size matters: variation in the diet of chick and adult crested terns. Marine Biology 156: 1765-1780.

Mullers RH, Navarro RA, Daan S, Tinbergen JM, Meijer HA. 2009. Energetic costs of foraging in breeding Cape gannets Morus capensis. Marine Ecology Progress Series 393: $161-171$

Ryan PG. 2017. Perch-hunting Swift Terns. Promerops 307: 19.

Stienen EW, Brenninkmeijer A. 1999. Keep the chicks moving: how Sandwich terns can minimize kleptoparasitism by black-headed gulls. Animal Behaviour 57: 1135-1144.

Stienen EW, Brenninkmeijer A, Courtens W. 2015. Intra-specific plasticity in parental investment in a long-lived single-prey loader. Journal of Ornithology 156: 699-710.

Wilson RP, Ryan PG, James A, Wilson MPT. 1987. Conspicuous coloration may enhance prey capture in some piscivores. Animal Behaviour 35: 1558-1560.

Ydenberg RC. 1994. The behavioral ecology of provisioning in birds. Ecoscience 1: 1-4. 


\section{FIGURES}

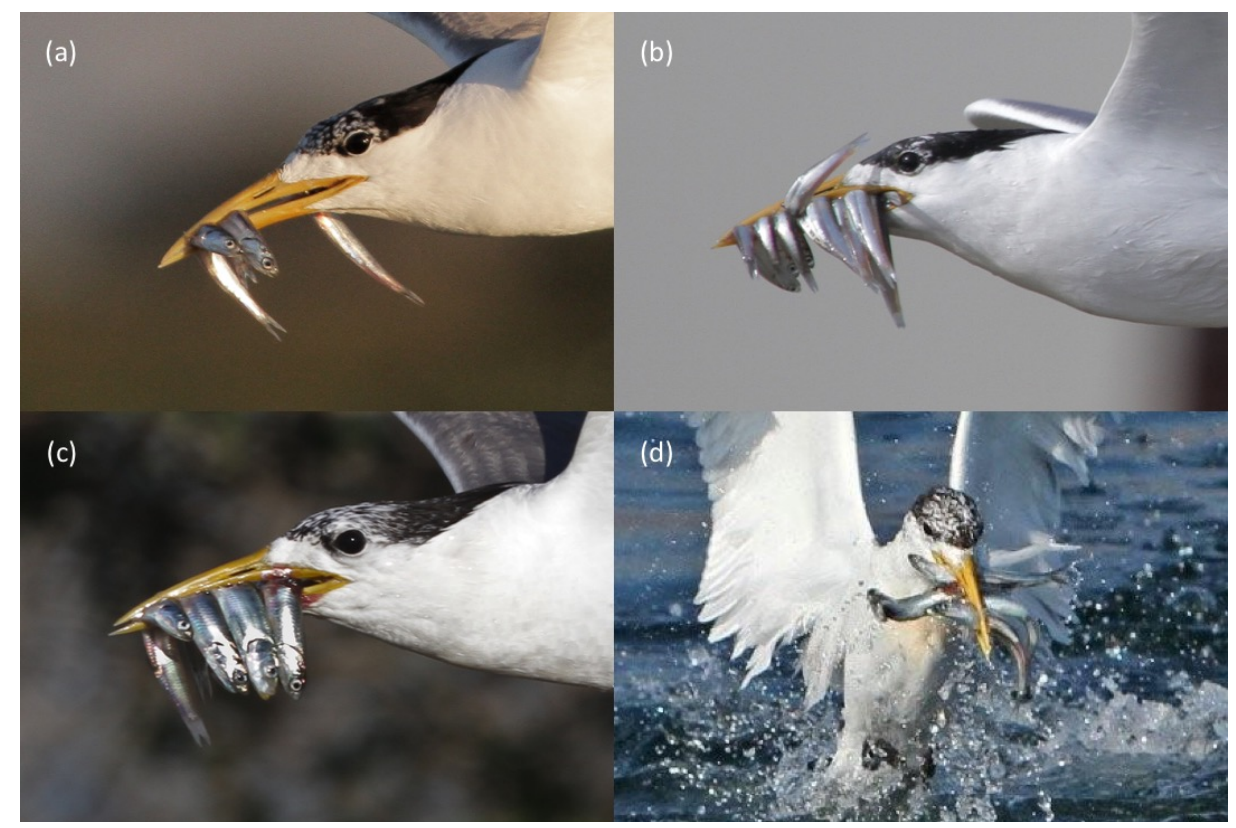

Figure 1: Examples of multi-prey loads returned to the colony by adult Greater Crested Terns breeding on Robben Island (2013-2015). Multi-prey loads including (a) three Anchovies; (b) 11 Anchovies; (c) mixed-species prey load including three Anchovies and one (the third from the left) Sardine (photos DG); and (d) an adult emerging at the sea-surface with five Anchovies captured in a single dive, because images taken before the bird entered the water confirmed it was not carrying any fish (Photo Barrie Rose). 


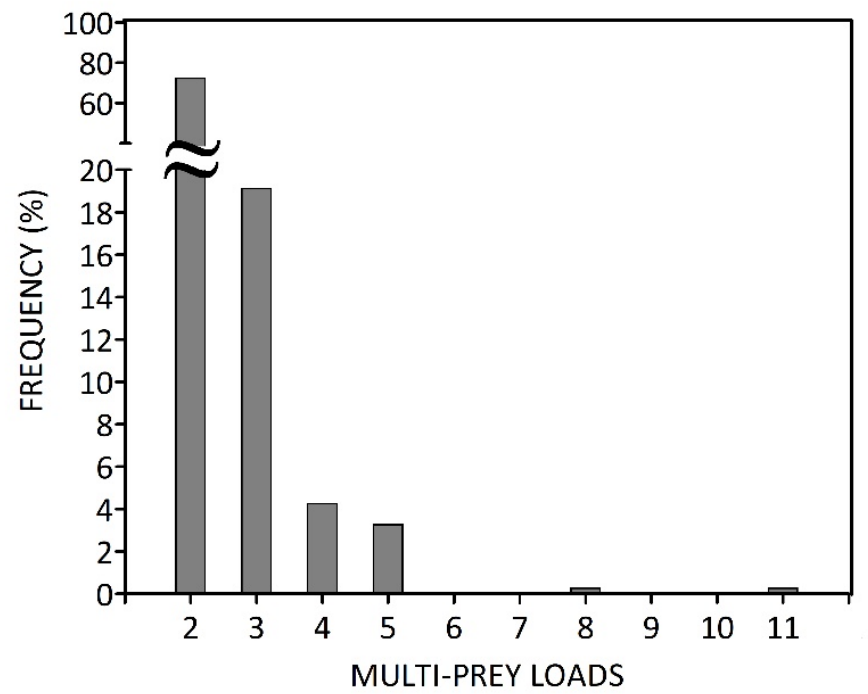

Figure 2: Frequency distribution of multi-prey loads $(n=305 ; 1.3 \%$ of all loads) carried by provisioning Greater Crested Terns breeding on Robben Island (2013-2015), arranged by number of prey carried in each load. 


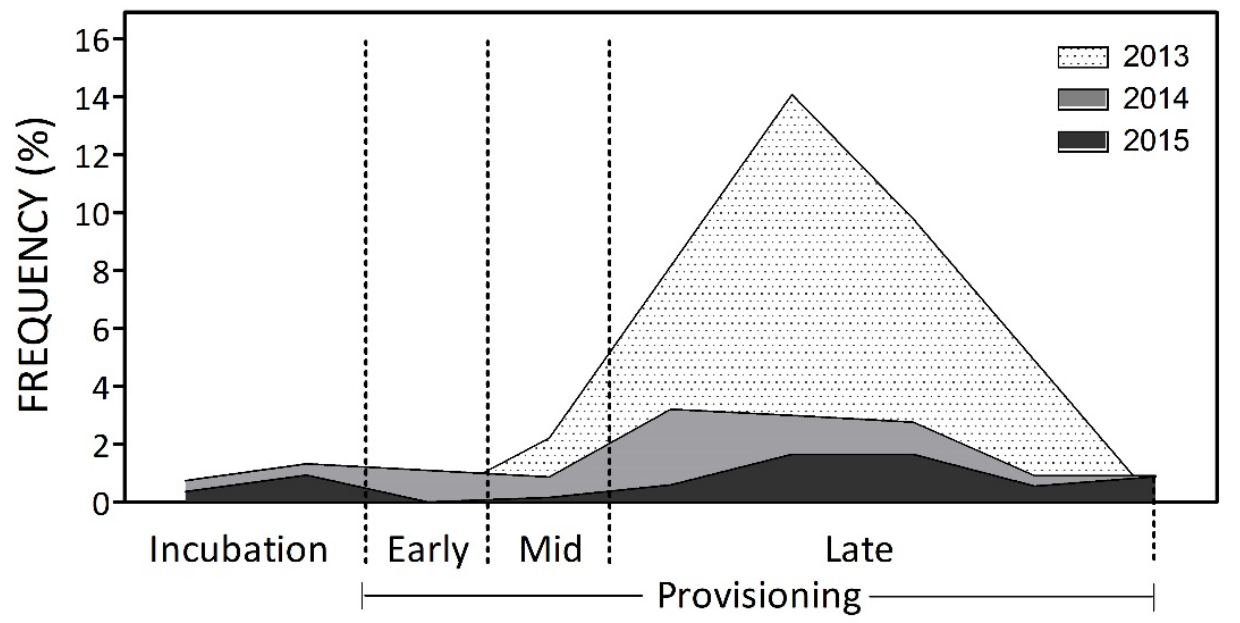

Figure 3: Frequency distribution of multi-prey loads ( $n=305 ; 1.3 \%$ of all loads) carried by provisioning Greater Crested Terns breeding on Robben Island across breeding stages, 2013-2015. 


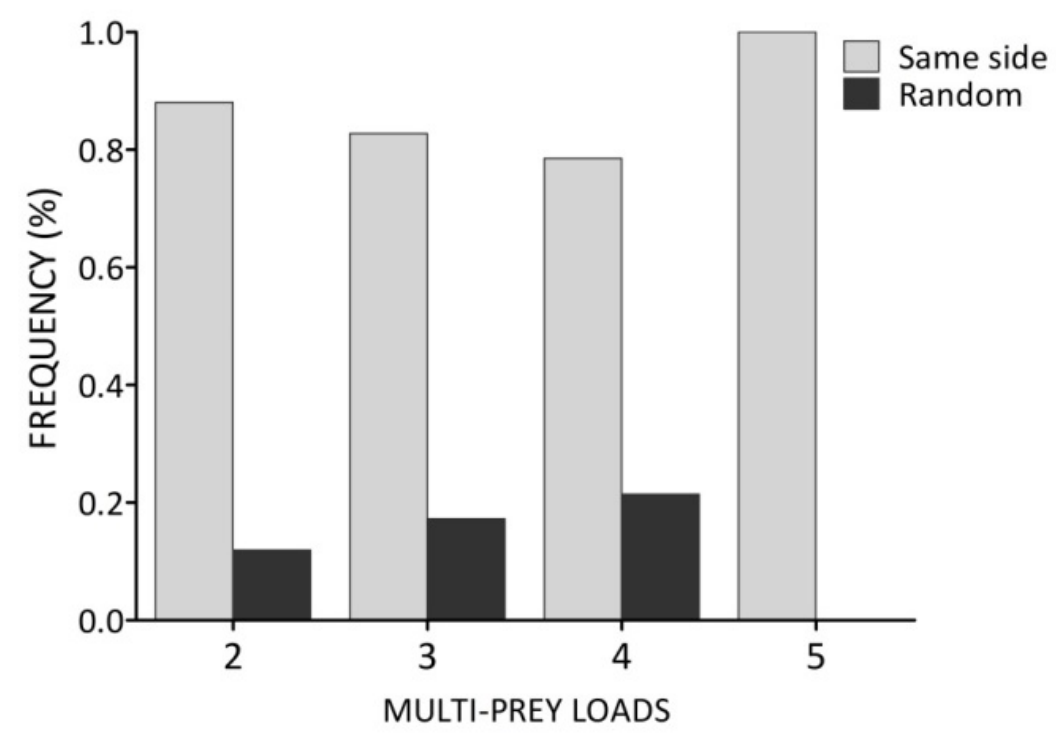

Figure 4: Frequency distribution of multi-prey loads with fish arranged on the same side (grey bars) and random (black bars) carried by provisioning Greater Crested Terns breeding on Robben Island (2013-2015), arranged by number of prey carried in each load. 